\title{
A Retrospective Comparison Study between the Effectiveness and Safety of Fixed Dose Combination of Vildagliptin versus Sitagliptin with Metformin in Type 2 Diabetes Mellitus Patients
}

\author{
Ndayishimye Samuel*, Prudence A. Rodrigues \\ PSG College of Pharmacy, Pharmacy Practice, Peelamedu, Coimbatore-641004, Tamil Nadu, INDIA.
}

\begin{abstract}
Aim: To compare the effectiveness and safety of fixed dose combination of vildagliptin $50 \mathrm{mg}$ versus sitagliptin 50mg with metformin 500mg in Type 2 Diabetes Mellitus patients. Method: Retrospectively 160 subjects were divided into two groups: A and $B$, in group A 80 subjects received a fixed dose combination of sitagliptin $50 \mathrm{mg}$ with metformin $500 \mathrm{mg}$ and 80 subjects in group $B$ received a fixed dose combination of vildagliptin $50 \mathrm{mg}$ with metformin $500 \mathrm{mg}$ for a period of 24 weeks. Glycated hemoglobin, fasting plasma glucose, postprandial glucose, bodyweight, potassium, microalbuminurea and creatinine were evaluated as outcomes parameters while safety was evaluated by reporting adverse event including hypoglycemic effect. Results: Both groups have shown a greater reduction in plasma glucose parameter: glycated hemoglobin reduced up to $0.97 \%(P<0.000)$ for vildagliptin group versus $0.928 \%(P<0.000)$ in sitagliptin group, fasting plasma glucose reduced up to $27.46 \mathrm{mg} / \mathrm{dl}(P<0.000)$ in vildagliptin group versus $20.925 \mathrm{mg} / \mathrm{dl}(P<0.019)$ for sitagliptin and postprandial glucose reduced up to $42.25 \mathrm{mg} / \mathrm{dl}(P<0.000)$ for vildagliptin versus $35.260 \mathrm{mg} / \mathrm{dl}(P<0.000)$ for sitagliptin. There were no significant alteration in kidney parameters in both groups: potassium, creatinine, micro albuminurea, body weight was increased by one I kilogram $(1.02 \mathrm{~kg})$ in sitagliptin group whereas it was reduced by $0.47 \mathrm{~kg}$ in vildagliptin group. The incidence of hypoglycemic effect were comparable less in both group $6.25 \%$ in vildagliptin group versus $5 \%$ in sitagliptin group other adverse drug reactions GIT was mild in both group did not require any alteration or discontinuation of the drugs. Conclusion: Both drugs are effective and safe in the management of type 2 diabetes mellitus. These drugs improve plasma glucose and are safe from hypoglycemic effect and they are not associated with the increase of body weight. However, vildagliptin offer a superior benefit over sitagliptin in the management of type 2 diabetes mellitus
\end{abstract}

Key words: Type 2 Diabetes Mellitus, Sitagliptin, Vildagliptin, Metformin.

\section{INTRODUCTION}

Type 2 Diabetes Mellitus (T2DM) is a chronic metabolic disorder occur due to the body does not respond to the insulin produced from pancreas ${ }^{1}$ or due to a decreased secretion of insulin ${ }^{2,3}$ (or) sometime a combination of the two. ${ }^{4}$ It is characterized by rised of blood glucose level, ${ }^{5}$ increased thirst, frequent urination, increased hunger, retardation of wound healing etc. ${ }^{6}$ according to the data International Diabetes Federation (IDF) in the last three decades the incidence of diabetes mellitus has boosted from 30 million in 1985 to 425 million in 2018, and it is set to reach 629 million by 2045 When it is not appropriately managed ${ }^{7,8}$ the management of diabetes require a combination of drug therapy and life style modifications. ${ }^{9}$ British National Institute for Health and Care Excellence (NICE), the American Diabetes Association (ADA) and the European
DOI: 10.5530/ijopp.11.4.37

Address for correspondence: Ndayishimye Samuel, PSG College of Pharmacy, Pharmacy Practice, Peelamedu, Coimbatore- 641004, INDIA. Phone no: +91 8220238200 Email Id: ndayisamukvm@gmail. com

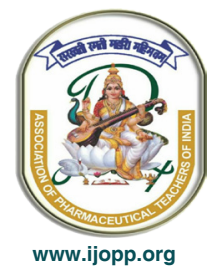


Association for the Study of Diabetes (EASD) along with life style modification: recommend early intervention with single oral monotherapy antidiabetic agents ${ }^{10}$ In Types 2 diabetes mellitus although monotherapy may be adequate initially, a large number of patients do not achieve adequate glycemic control. ${ }^{11}$ Dose adjustment and progression to multiple diabetes therapies are required to maintain target $\mathrm{HbA1c}$ levels. Metformin is the first line drug for management of hyperglycemic recommended by NICE, ADA and EASD which can be used as single or in combination therapy. ${ }^{10,12}$ metformin works by increasing glucose uptake and improving sensitivity of body tissues to insulin ${ }^{13,14}$ which helps the insulin produced by body to be efficaciously used to control blood sugar and it also acts by suppressing hepatic glucose production. Nausea, abdominal discomfort, vomiting and diarrhea are possible side effects of metformin..$^{15}$ In addition to metformin therapy a health care practitioner also recommends lifestyle changes: such as losing weight, eating healthy diet. ${ }^{16}$ Only a single drug therapy is suggested when HBA1c is less than $7.5 \%$ whereas if glycated hemoglobin is above $9 \%$ a combination of two or more drug therapy ${ }^{17,18}$ are required. After metformin (a Biguanide) prescribed as first-line drug; sulfonylurea, DPP-4 inhibitors, SGLT2 inhibitors, Meglitinides, GLP-1 analogues or insulin can be added to metformin. However, in the current clinical practice the American Diabetes Association/European Association for the Study of Diabetes consensus algorithm for the treatment of Type 2 DM endorses the use of newer class of drugs, the incretins or incretin-based therapies such as DPP-4 inhibitors, either alone or in combination. ${ }^{19}$

The desired goal in all is to control blood glucose levels and to prevent microvascular and macrovascular complications ${ }^{20}$ When a fixed dose combination of metformin with DPP-4 inhibitors is used it increases compliance in patients rather than taking a free drug combination of metformin with other oral anti-diabetic agents; Under this category of dipeptidyl peptidase-4 inhibitors: ${ }^{21}$ Sitagliptin was approved by FDA in 2006, vildagliptin approved in 2008, saxagliptin approved in 2009 and Alogliptin in year 2010 and last Linagliptin was approved by FDA in year 2011. DPP-4 Inhibitor are incretin-based therapy which reduce blood sugar by promoting insulin secretion, decreasing glucagon production, ${ }^{22}$ delaying gastric emptying, increasing satiety without inducing hypoglycemia and there are also not associated with weight gain ${ }^{23}$ among the diabetes mellitus patients. Sitagliptin has a good oral bioavailability, which goes up to 87 percent, ${ }^{24}$ Its half-life is $14.4 \mathrm{hrs}$ there is dose dependent inhibition of DPP-4 activity and approximately 80 percentage of enzyme activity is inhibited for $24 \mathrm{hr}$ at $100 \mathrm{mg} .{ }^{12}$ Studies have shown that
Sitagliptin has no clinical significant interactions with other medications. ${ }^{25}$ The drug is excreted through the urine by the tubular secretions. Hence, renal function should be monitored in case of renal insufficiency dose can be reduced to $50 \mathrm{mg}$ and $25 \mathrm{mg}$ for a creatinine clearance of 30 to $50 \mathrm{~mL} / \mathrm{minute}$ and less than $30 \mathrm{~mL} / \mathrm{min}$ respectively. ${ }^{26}$ Vildagliptin is quickly absorbed and the maximum plasma concentration can be achieved between 1 hour and $1.5 \mathrm{hr}^{27}$ and almost $85 \%$ of the drug is absorbed the final half-life is $2.8 \mathrm{hr}^{28}$ but the complete removal from the body can last up to 7 days and it is mostly excreted from the urine while a remaining least fraction of absorbed drug is eliminated through feces. ${ }^{29}$ Due to its short half-life when it is used as monotherapy or in combination with other anti-diabetes drugs a daily required dose is $100 \mathrm{mg}$ which is given as single or in divided doses.

This study is aimed to compare the efficacy and safety of Vildagliptin $50 \mathrm{mg}$ versus Sitagliptin $50 \mathrm{mg}$ fixed dose combination with metformin 500mg in Types 2 diabetes mellitus patients.

\section{METHODOLOGY}

Retrospectively data were collected from medical record department, a total number of 160 subjects were divided into two group: Group A and B respectively, 80 patients from group A received Sitagliptin in fixed dose combination with metformin $500 \mathrm{mg}$ whereas 80 patients from group B received Vildagliptin 50mg in fixed dose combination with metformin $500 \mathrm{mg}$. the study was conducted at PSG Hospitals a tertiary care hospitals in both group patient with Type 2 Diabetes Mellitus prescribed with either only a fixed dose combination of vildagliptin $50 \mathrm{mg}$ with metformin $500 \mathrm{mg}$ or a fixed dose combination of sitagliptin $50 \mathrm{mg}$ with metformin $500 \mathrm{mg}$ in age ranging from 30-75 year old who visited hospital at least two times within 6 months study period were included, patient who took other antidiabetic drugs were excluded Glycated hemoglobin, fasting plasma glucose, postprandial glucose, bodyweight, potassium and creatinine, microalbuminurea were evaluated as outcomes parameters while safety was evaluated by reporting adverse event including hypoglycemic effect in both group selected for the study.

\section{RESULTS}

During the six month period of follow-up the results of the fixed dose combination of either vildagliptin or sitagliptin with metformin in group A and group B: Both groups have shown a greater reduction in plasma 
Table 1: Patient characteristic before and after 24 weeks of the study.

\begin{tabular}{|c|c|c|c|c|}
\hline & \multicolumn{2}{|c|}{ Vildagliptin Group (N=80) } & \multicolumn{2}{|c|}{ Sitagliptin Group $(\mathrm{N}=80)$} \\
\hline & Before & After & Before & After \\
\hline AGE (Year) & \multicolumn{2}{|c|}{$59.22 \pm 8.50$} & \multicolumn{2}{|c|}{$56.80 \pm 10$} \\
\hline GENDER( F/M) & \multicolumn{2}{|c|}{$38 / 42$} & \multicolumn{2}{|c|}{$24 / 56$} \\
\hline $\mathrm{FPG}$ (in $\mathrm{mg} / \mathrm{dl}$ ) & $169.72 \pm 55.47$ & $142.26 \pm 33.26$ & $171.31 \pm 67.17$ & $150.38 \pm 52.38$ \\
\hline PPG(in mg/dl) & $233.90 \pm 50.77$ & $191.65 \pm 40.11$ & $234.41 \pm 60.95$ & $199.15 \pm 55.74$ \\
\hline HBA1C percentage & $8.64 \pm 2.09$ & $7.67 \pm 0.97$ & $9.02 \pm 2.20$ & $8.09 \pm 1.36$ \\
\hline CREATININE(in mg/dl) & $1.35 \pm 1.19$ & $1.22 \pm 0.95$ & $1.04 \pm 0.86$ & $1.07 \pm 0.92$ \\
\hline POTASSIUM(meq/dl) & $4.57 \pm 0.5$ & $4.55 \pm 0.48$ & $4.36 \pm 0.61$ & $4.35 \pm 0.53$ \\
\hline ALBUMINE(in mg/dl) & $3.95 \pm 0.29$ & $3.96 \pm 0.30$ & $4.11 \pm 0.47$ & $4.05 \pm 0.44$ \\
\hline BODY WEIGHT (in Kg) & $70.41 \pm 12.85$ & $69.94 \pm 12.39$ & $68.28 \pm 13.24$ & $69.3 \pm 12.88$ \\
\hline
\end{tabular}

F: Female, M: male, Kg=kilogram, mg/dl = milligram per deciliter meq/dl= milieqivalent per deciliter $\mathrm{N}=$ Total Number $\pm=$ Mean SD

glucose parameter as Table 1: glycated hemoglobin reduced from $8.64 \% \pm 2.09 \%$ to $7.67 \% \pm 0.97 \%$ up to $0.97 \%(P<0.000)$ was reduced for vildagliptin group versus a change from $9.02 \% \pm 2.20 \%$ to $8.09 \% \pm 1.36 \%$ a total number of $0.928 \%(P<0.000)$ was reduced in sitagliptin group, fasting plasma glucose reduced up to $169.72 \pm 55.47 \mathrm{mg} / \mathrm{dl}$ to $142.26 \pm 33.26 \mathrm{mg} / \mathrm{dl}$ a total reduction of $27.46 \mathrm{mg} / \mathrm{dl}(P<0.000)$ in vildagliptin group versus $171.31 \pm 67.17$ to $150.38 \pm 52.38 \mathrm{mg} / \mathrm{dl}$ a total reduction of $20.925 \mathrm{mg} / \mathrm{dl}(P<0.019)$ for sitagliptin and postprandial glucose reduced from $233.90 \pm 50.77 \mathrm{mg} / \mathrm{dl}$ to $191.65 \pm 40.11 \mathrm{mg} / \mathrm{dl}$ a total reduction of $42.25 \mathrm{mg} / \mathrm{dl}$ $(P<0.000)$ for vildagliptin was seen versus a reduction from $234.41 \pm 60.95 \mathrm{mg} / \mathrm{dl}$ to $199.15 \pm 55.74 \mathrm{mg} / \mathrm{dl} \mathrm{a}$ total reduction of $35.260 \mathrm{mg} / \mathrm{dl}(P<0.000)$ for sitagliptin.

There were no significant alteration in kidney parameters in both groups: potassium, creatinine, microalbuminurea were remained near closer to the baseline for the period of the study which indicate that both drugs have a renal protection in the management of Type 2 diabetes mellitus patients, creatinine has reduced from $1.35 \pm 1.19$ to $1.22 \pm 0.95$ in vildagliptin whereas it has changed from $1.04 \pm 0.86$ to $1.07 \pm 0.92$, potassium changed from $4.57 \pm 0.5$ to $4.55 \pm 0.48$ in Vildagliptin versus to $4.36 \pm 0.61$ to $4.35 \pm 0.53$ in sitagliptin, microalbuminurea changed from $3.95 \pm 0.29$ to $3.96 \pm 0.30$ in Vildagliptin to $4.11 \pm 0.47$ to $4.05 \pm 0.44$ in Sitagliptin.

Body weight was increased from $68.28 \pm 13.24 \mathrm{Kg}$ to $69.30 \pm 12.88 \mathrm{~kg}$ near weight increased by one 1 kilogram $(1.02 \mathrm{~kg})$ from the baseline in sitagliptin group whereas it was reduced from to $70.41 \pm 12.85 \mathrm{~kg}$ to $69.94 \pm 12.39 \mathrm{~kg}$ a total of $0.47 \mathrm{~kg}$ was reduced from the baseline in vildagliptin group. The hypoglycemic effect and other adverse effect during the period of study patients who had co-morbidities such as hypertension, coronary artery diseases, myocardial infarction, cerebrovascular accident (strokes), dyslipidemia and microvascular complications such as nephropathy, retinopathy and neuropathy didn't show any potential effect for discontinuations of the treatment or alterations of drug therapy during the period of the Study. $6.25 \%$ of patient who took $50 \mathrm{mg}$ Vildagliptin in fixed dose combination with metformin have developed hypoglycemic effect whereas there were $5 \%$ cases was found in the Sitagliptin group. The other minor adverse effect such as nausea and vomiting were comparable less for both groups.

\section{DISCUSSION}

Type 2 Diabetes Mellitus is commonly seen in middle age individuals especially after 50 years of age ${ }^{30}$ in our study the mean average in age was $59.22 \pm 8.50$ in Vildagliptin group and $56.8 \pm 10$ in Sitagliptin group which show collaboration with previous study where the mean average age was 58.3 years, ${ }^{31,32} \mathrm{~A}$ difference of $0.04 \%$ in glycated hemoglobin was seen in Vildagliptin group over Sitagliptin which is comparable to a comparison study of the randomized trials conducted in Japan by signorovitch et al. showed a difference of $0.3 \%$ of reduction shown by Vildagliptin over sitagliptin..$^{33}$ in their study entitled efficacy and safety of Vildagliptin in clinical practice results of Vildagliptin-study demonstrated an average reduction of $0.9 \%$ in mean glycated hemoglobin after a six months of the treatment by Vildagliptin and Metformin which almost similar to the results of this study. Previous studies conducted by Reasner et al. ${ }^{34}$ Pérez-Monteverde et al..$^{35}$ and Weinstein et al. ${ }^{36}$ have proven that combination of Sitagliptin and metformin produces significant improvement in glycemic parameters such as FPG, PPG and $\mathrm{HbA1c}$ and also improve adherence in type 2 diabetes mellitus patient.

Renal parameters such as creatinine, potassium and microalbuminurea were evaluated on both group i.e. 
Sitagliptin and Vildagliptin and there was no marked change in both groups which is similar to a study conducted by Naoto Kamatani $e t$ al. ${ }^{37}$

Body Weight has been increased by $1.02 \mathrm{~kg}$ in Sitagliptin group and a decreased to $0.47 \mathrm{~kg}$ in mean average which is insignificant from the baseline which was in accordance with a study done by Xiaoling $e t$ al. ${ }^{38}$ in a meta-analysis entitled DPP-4I treatment in Chinese type 2 diabetes mellitus and Mousa Al Omar et al. ${ }^{39}$ in their study entitled Vildagliptin efficacy in combination with metformin among Jordanian patients with type 2 diabetes mellitus inadequately controlled with metformin.

The incidence of hypoglycemia was almost similar in both the study groups that is $6.25 \%$ for Vildagliptin and $5 \%$ for Sitagliptin, which is similar to a previous study by chun-jun li et al. ${ }^{1}$ another study by Deacon cp et al. the expert's opinions on DDP-4I confirm that that Sitagliptin and Vildagliptin are well tolerated on hypoglycemic effect and body weight gaining. ${ }^{40}$

There was no potential cardiovascular event reported during a total duration of this study and it is confirmed with a study by Edoardo Mannucci et al. ${ }^{41}$ on their systematic review of integrated analyses and RCT on the cardiovascular safety of incretin based therapies in type 2 diabetes. The incidence of adverse drug reactions was mild in both groups and did not require any alteration or discontinuation of study drugs.

\section{CONCLUSION}

This comparison study between a fixed dose combination of Sitagliptin and Vildagliptin with metformin show that both drugs are effective and safe in the management of Type 2 diabetes mellitus. These drugs improve plasma glucose and are safe from hypoglycemic effect and they are not associated with the increase of body weight. However, Vildagliptin offer a superior benefit over Sitagliptin in the management of Type 2 diabetes mellitus

\section{ACKNOWLEDGEMENT}

We are pleased to thank Dr. R. Senthil Kumar MD, MRCP, Assistant Professor, Department of Endocrinology, PSG Hospitals for granting us permission and necessary support to carry out this study in his department. We express our sincere thanks to DR. M. Ramanathan, M.Pharm, Ph.D., Principal of PSG College of Pharmacy, coimbatore for providing the necessary facilities and amenities to carry out our study with great ease, we express our special note of thanks to Dr. Andhuvan
A. Gandhi M.Pharm, PhD., Associate Professor, Department of Pharmacy Practice, PSG College of Pharmacy, Coimbatore for her advice, sharing her constrictive and valuable ideas for completion of this study. We thank Dr. Vimalkumar Govindan, MSc. FRCS., Director of Medical Record Department and his team for allowing us to use MRD and helping hand in data collection. We thank our friend for their comments and ideas which are more important for successful completion of this work

\section{CONFLICT OF INTEREST}

The authors announced that there is no conflict of interest regarding this work of study.

\section{ABBREVIATIONS}

ADA: American Diabetes Association; BID: Twice Daily; CGM: Continuous Glucose Monitoring; DM: Diabetes Mellitus; DPP-4I: Di Peptidyl Peptidase 4 Inhibitors; EASD: European Association for the Study of Diabetes; FDA: Food and Drug Administration; FPG: Fasting Plasma Glucose; GLP-1: Glucagon -Like Peptide 1 analogues; HBA1C: Glycated Hemoglobin; IDF: International Diabetes Federation; NICE: British National Institute for Health and Care Excellence; PPG: Post Prandial Glucose; SGLT-2: Sodium Glucose Co-Transporter -2; T2DM: Type 2 Diabetes Mellitus.

\section{SUMMARY}

A fixed dose combination of vildagliptin or sitagliptin with metformin controls plasma glucose in Type 2 diabetes mellitus patients. In addition to this it also increase patient compliance.

\section{REFERENCES}

1. Chun-Jun L, Xiao-Juan L, Lian B. Efficacy and Safety of Vildagliptin, Saxagliptin or Sitagliptin as Add-On Therapy in Chinese Patients with Type 2 Diabetes Inadequately Controlled With dual Combination of Traditional Oral Hypoglycemic agents. Diabetology and Metabolic Syndrome. 2014;6(1):69.

2. Chitrabhanu B, Stephen CLG. Safety and Efficacy of Sitagliptin-Metformin in Fixed Combination for the Treatment of Type 2 Diabetes Mellitus. Endocrinology and Diabetes. 2013;6:25-37.

3. Elisa G, Laura N, Aurora P. Combination therapy with metformin plus vildagliptin in type 2 diabetes mellitus. Expert Opin Pharmacother. 2012;13(9):1377-84.

4. Lee SA, Koh G, Cho SJ, Yoo SY, Chin SO. Correlation of Glypican-4 Level with Basal Active Glucagon-Like Peptide 1 Level in Patients with Type 2 Diabetes Mellitus. Endocrinol Metab. 2016;31(3):439-45.

5. Rosenstock J, Brazg R, Andryuk PJ, Lu K, Stein P. Efficacy and safety of the Dipeptidyl Peptidase-4 Inhibitor sitagliptin added to ongoing pioglitazone therapy in patients with type 2 diabetes: a 24-week, multicenter, randomized, doubleblind, placebo-controlled parallel group study. Clin Ther. 2006;28(10):1556-68. 
6. Masaya S, Rimei N, Taiga I, Daisuke T. Comparison of vildagliptin twice daily vs. Sitagliptin once daily using Continuous Glucose Monitoring (CGM): Crossover pilot study (J-VICTORIA study). Cardiovascular Diabetology. 2012;11(1):92.

7. Aguiree F, Brown A, Cho NH, Dahlquist G, Dodd S, Dunning T, et al. IDF Diabetes Atlas. 2013

8. Guariguata L, Whiting D, Weil C, Unwin N. The International Diabetes Federation diabetes atlas methodology for estimating global and national prevalence of diabetes in adults. Diabetes Res Clin Pract 2011;94(3):322-32.

9. Nandita BS, Deepak NP, Kamlesh M, Palandurkar, et al. Impact of lifestyle modification on Glycemic control in patients with Type 2 Diabetes Mellitus. Indian J Endocrinol Metab. 2013;17(6):1030-9.

10. American Diabetes Association. Standards of medical care in diabetes -a 2016. Diabetes Care. 2016;39(suppl 1):S1-S106.

11. Herman G, Stevens C, Van DK. Pharmacokinetics and Pharmacodynamics of Sitagliptin, an Inhibitor of Dipeptidyl Peptidase IV, in Healthy Subjects: results from two randomized, double-blind, placebo-controlled studies with single oral doses. Clin Pharmacol Ther. 2005;78(6):675-88.

12. Papanas N, Maltezis E. Metformin: A Review of its use in the Treatment of Type 2 Diabetes. Clin Med Ther. 2009;1:1367-81.

13. Miller RA, Birnbaum MJ. An energetic tale of AMPK-independent effect of metformin. J Clin Invest 2010;120(7):2267-70

14. Zhou G, Myers R, Li Y. Role of AMP-Activated Protein Kinase in mechanism of metformin action. J Clin Invest. 2001;108(8):1167-74.

15. Janumet TM. (Sitagliptin/Metformin Hydrochloride) tablets [package insert] white house station. NJ: Merck pharmaceuticals, inc. 2012.

16. Juan J, Iciar M. Update on the treatment of Types 2 Diabetes Mellitus. World J Diabetes. 2016;7(17):354-95.

17. Inzucchi SE, Bergenstal RM, Buse JB, et al. Medical management of hyperglycemia in Types 2 Diabetes: a patient-centered approach. Diabetes Care. 2012;35(6):1364-79.

18. Simonson GD, Cuddihy RM, Reader D, Bergenstal RM. International Diabetes center Treatment of Type 2 Diabetes glucose algorithm. Diabet Manag. 2011;1(2):175-89.

19. Cobble M. Differentiating among Incretin-based therapies in the management of patients with Type 2 diabetes mellitus. Diabetol Metab Syndr. 2012;4(8):1-10.

20. Emerging Risk factors collaboration: Diabetes Mellitus, Fasting Glucose and Risk of cause-specific death. N Engl J Med. 2011;364(9):829-41.

21. Vishal G, Sanjay K. Choosing a Gliptin. Indian J Endocrinol Metab. 2011;15(4):298-308

22. Drucker DJ, Nauck MA. The Incretin system: Glucose-Like Peptide 1 Receptor agonists and Dipeptidyl Peptidase-4 Inhibitors in Type 2 Diabetes. Lancet. 2006;368(9548):1696-705.

23. Powers AC, Alessio D. Endocrine pancreas and pharmacotherapy of diabetes mellitus and hypoglycemia. The Pharmacological Basis of Therapeutics, New York: McGraw-Hill. 2011;12:1237-73.

24. Bergman A, Ebel D, Liu F. Absolute bioavailability of Sitagliptin, an oral Dipeptidyl Peptidase-4 Inhibitor, in healthy volunteers. Biopharm Drug Dispos. 2007;28(6):315-22.

25. Herman GA, Stein PP, Thornberry NA, Wagner JA. Dipeptidyl peptidase-4 inhibitors for the treatment of Type 2 diabetes: focus on Sitagliptin. Clin Pharmacol Ther. 2007;81(5):761-7.
26. Hermansen K, Kipnes M, Luo E. Sitagliptin study 035group. Efficacy and safety of the Dipeptidyl peptidase-4 inhibitor, Sitagliptin, in patients with Type 2 diabetes mellitus inadequately controlled on Glimepride alone or on Glimepride and metformin. Diabetes Obes Metab. 2007;9(5):733-45

27. He YL, Barilla D, Ligureos-Saylan M. The pharmacokinetics and DPP-4 inhibition of LAF237 in healthy volunteers [abstract]. J ClinPharmacol 2004;44(10):1212.

28. Yan-Ling $\mathrm{H}$. Clinical Pharmacokinetics and Pharmacodynamics of Vildagliptin. Clin. Pharmacokinet. 2012;51(3):147-62.

29. He YL, Sabo R, Campestrini J, Wang Y, Riviere GJ, Nielsen JC, et al. The effect of age, gender and body mass index on the pharmacokinetics and pharmacodynamics of vildagliptin in healthy volunteers. $\mathrm{Br} \mathrm{J}$ Clinpharmacol. 2008;65(3):338-46.

30. Jeon HJ, Oh TK. Comparison of vildagliptin-metformin and glimepiridemetformin treatments in Type 2 diabetic patients. Diabetes Metab J. 2011;35(5):529-35.

31. Wolfgang K, Valentina L. Effectiveness of vildagliptin as add-on to Metformin Monotherapy among uncontrolled Type 2 Diabetes Mellitus patients in a realworld setting. Journal of Diabetes. 2018;10(1):68-72.

32. Signorovitch JE, Wu EQ, Swallow E, Kantor E, Fan L, Gruenberger JB. Comparative efficacy of vildagliptin and sitagliptin in Japanese patients with Type 2 diabetes mellitus: a matching-adjusted indirect comparison of randomized trials. Clin Drug Investig. 2011;31(9):665-74.

33. Bleuher M, Kurz I, Dannenmaier S. Efficacy and safety of vildagliptin in clinical practice-results of the provil-study. World J Diabetes. 2012;3(9):161-9.

34. Reasner C, Olansky L, Seck TL, Williams-Herman DE, Chen M, Terranella L, et al. The effect of initial therapy with fixed dose combination of sitagliptin and metformin compared with metformin monotherapy in patients with Type 2 diabetes mellitus. Diabetes Obes Metab. 2011;13(7):644-52.

35. Pérez-Monteverde A, Seck T, Xu L, Sisk CM, Williams-Herman DE, Engel SS, et al. Efficacy and safety of sitagliptin and the fixed-dose combination of sitagliptin and metformin vs. pioglitazone in drug-naïve patients with Type 2 diabetes. Int J Clin Pract. 2011;65(9):930-8.

36. Wainstein J, Katz L, Engel SS, Xu L, Golm GT, Hussain S, et al. Initial therapy with the fixed-dose combination of Sitagliptin and metformin results in greater improvement in glycaemia control compared with pioglitazone monotherapy in patients with Type 2 diabetes. Diabetes Obes Metab. 2012;14(5):409-18.

37. Naoto K, Taiya K. Comparison between the clinical efficacy of Linagliptin and Sitagliptin. J Diabetes Endocrinol. 2013;4(4):51-4.

38. Xiaoling C, Xueying G, Wenjia Y, et al. DPP-4 Inhibitor Treatment in Chinese Type 2 Diabetes Patients: A Meta-Analysis. Diabetes technology therapeutics. 2016;18(12):1-10.

39. Mousa AO, Yousef K, Ali SD. Vildagliptin efficacy in combination with metformin among Jordanian patients with Type 2 diabetes mellitus inadequately controlled with metformin. Journal of Drug Assessment. 2016;5(1):29-33.

40. Deacon CF, Ahren B, Holst JJ. Inhibitors of Dipeptidyl peptidase IV: a novel approach for the prevention and treatment of Type 2 diabetes?. Expert Opin Investig Drugs. 2004;13(9):1091-10.

41. Edoardo M, Matteo M. Cardiovascular safety of incretin-based therapies in Type 2 diabetes: systematic review of integrated analyses and randomized controlled trials. Adv Ther. 2017;34(1):1-40. 